\title{
Nitrergic Inhibition of Tachykininergic Neuro-Muscular Transmission via Cyclic GMP in the Hamster Ileum
}

\author{
Hayato MATSUYAMA ${ }^{1) *}$, Toshihiro $\mathrm{UNNO}^{1)}$, Seiichi KOMORI ${ }^{1)}$ and Tadashi TAKEWAKI ${ }^{2)}$ \\ ${ }^{1)}$ Laboratory of Veterinary Pharmacology and ${ }^{2)}$ Laboratory of Veterinary Physiology, Department of Veterinary Medicine, Faculty of \\ Applied Biological Science, Gifu University, 1-1 Yanagido, Gifu 501-1193, Japan
}

(Received 28 September 2010/Accepted 22 November 2010/Published online in J-STAGE 6 December 2010)

\begin{abstract}
The present study was designed to explore the inhibitory mechanism by nitric oxide (NO) of the tachykininergic neuro-muscular transmissions in the hamster ileum. In the presence of guanethidine $(1 \mu \mathrm{M})$, atropine $(0.5 \mu \mathrm{M})$, nifedipine $(0.1 \mu \mathrm{M})$ and apamin $(100 \mathrm{nM})$, electrical field stimuli (EFS; $0.5 \mathrm{~ms}$ duration, $15 \mathrm{~V}$ ) evoked non-adrenergic, non-cholinergic excitatory junction potentials (EJPs) in circular smooth muscle cells. The EJPs were markedly inhibited by the tachykinin NK1 receptor antagonists $\left[\mathrm{D}-\mathrm{Pro}^{4}, \mathrm{D}-\mathrm{Trr}^{7,9}\right]$ $\mathrm{SP}(4-11)(3 \mu \mathrm{M})$. Both the NO synthase inhibitor $\mathrm{N}^{\mathrm{G}}$-nitro-L-arginine methyl ester (L-NAME, $\left.200 \mu \mathrm{M}\right)$ and the soluble guanylate cyclase inhibitor $1 \mathrm{H}-[1,2,4]$ oxadiazolo-[4,3-a]quinoxalin-1-one (ODQ, $10 \mu \mathrm{M})$, did not affect on the resting membrane potentials, but enhanced the tachykininergic EJPs. In the presence of L-NAME $(200 \mu \mathrm{M})$, exogenously applied NO $(10 \mu \mathrm{M})$ and the membrane permeable analogue of guanosine 3',5'-cyclic monophosphate (cGMP), 8-bromoguanosine 3',5'-cyclic monophosphate (8-Br-cGMP, 3 $\mathrm{mM})$, significantly inhibited the tachykininergic EJPs. Application of EFS $(0.5 \mathrm{msec}$ duration, $15 \mathrm{~V})$ with trains of 20 pulses at $20 \mathrm{~Hz}$ increased amount of released substance P (SP). The release of SP was further increased by the treatment of L-NAME or ODQ, but markedly reduced by exogenously applied NO and 8-Br-cGMP. These results suggest that the endogenous NO may inhibit the tachykininergic neuro-muscular transmissions by the decrease of SP release from the tachykininergic neurons, possibly through a guanylate cyclasecGMP-dependent mechanism in the hamster ileum.

KEY WORDS: excitatory junction potential, nitric oxide, small intestine, smooth muscle, substance $\mathrm{P}$.
\end{abstract}

J. Vet. Med. Sci. 73(4): 453-458, 2011

In mammalian gastrointestinal tract, nitric oxide (NO) mediates inhibitory regulation of gut motility [5]. In the hamster small intestine, it has been reported that NO released from enteric neurons act on smooth muscle cells to open apamin-sensitive, $\mathrm{Ca}^{2+}$-activated $\mathrm{K}^{+}$channels, resulting in membrane hyperpolarization and muscle relaxation [13]. In addition to such direct action on smooth muscles, NO has been proposed to decrease intestinal motilities by inhibiting the release of excitatory neurotransmitters [ 3 , $27,28]$.

In the guinea-pig ileum, NO inhibits muscle contractions evoked by tachykininergic nerve stimulation [3, 28]. This effect may be partly brought about by the inhibitory action of NO on the smooth muscles. However, it is unclear whether NO also act on the tachykininergic neurons and affect neurotransmitter release.

The present study was therefore designed to explore the mechanisms of inhibitory regulation by nitrergic neurons of the tachykininergic neuro-muscular transimission. Since the nitrergic neuron is predominant inhibitory neurons and tachykininergic excitatory neurotransmission is present in the hamster ileum [2, 13, 14], we used this preparation and measured excitatory junction potentials and amount of released substance $\mathrm{P}$ (SP) elicited by enteric nerve stimulation using microelectrode technique and enzyme immunoas-

\footnotetext{
* Correspondence to: Matsuyama, H., Laboratory of Veterinary Pharmacology, Department of Veterinary Medicine, Faculty of Applied Biological Science, Gifu University, 1-1 Yanagido, Gifu 501-1193, Japan

e-mail: mhayato@gifu-u.ac.jp
}

say technique, respectively. The results suggest that endogenous NO act on the tachykininergic neurons to inhibit release of SP.

\section{MATERIALS AND METHODS}

All animal care and experimental procedures described below complied with the guidelines approved by the local animal ethics committee of the Faculty of Applied Biological Science, Gifu University.

Measurement of membrane potential responses: Tissue preparations and electrophysiological techniques used in the present study were similar to those described previously [13]. In brief, male Syrian hamsters (body weight: 80-120 g) were anesthetized with diethyl ether and exsanguinated via the carotid arteries. The whole ileum was quickly excised and immersed in physiological salt solution (PSS) composed of $(\mathrm{mM}) ; \mathrm{NaCl} 137, \mathrm{KCl} 4.0, \mathrm{NaH}_{2} \mathrm{PO}_{4} 0.5$, $\mathrm{NaHCO}_{3}$ 11.9, $\mathrm{CaCl}_{2}$ 2.0, $\mathrm{MgCl}_{2} 1.0$ and glucose 5.6. The ileum was divided into small segments (1 cm in length), and the segment was gently stretched and fixed with pins to a rubber block in a $4 \mathrm{~m} l$ volume of experimental chamber maintained at $30^{\circ} \mathrm{C}$. The segment was continuously perfused at $3 \mathrm{ml} \mathrm{min}{ }^{-1}$ with PSS prewarmed at $30^{\circ} \mathrm{C}$ and oxygenated by bubbling with a $95 \% \mathrm{O}_{2} / 5 \% \mathrm{CO}_{2}$ gas mixture. Atropine $(0.5 \mu \mathrm{M})$, guanethidine $(1.0 \mu \mathrm{M})$ and nifedipine $(0.1 \mu \mathrm{M})$ were added in the PSS throughout the experiments. Membrane potential responses were recorded using a conventional glass microelectrode filled with $3 \mathrm{M} \mathrm{KCl}$ with resistances of 50-80 M $\Omega$. When smooth muscle cells 
of the outer layer of the preparations were penetrated with microelectrode, the membrane potentials were electrically quiescent with resting membrane potential of around -40 $\mathrm{mV}$. These cells were taken as longitudinal smooth muscle cells. If the electrode was inserted further into the deep layers, the resting membrane potentials were more negative (around $-45 \sim-50 \mathrm{mV}$ ) and often exhibited slow wave-like fluctuations [10]. These cells were regarded as circular smooth muscle cells. Intrinsic non-adrenergic and non-cholinergic (NANC) nerves were stimulated by transmural electrical field stimuli (EFS; $0.5 \mathrm{msec}$ duration $15 \mathrm{~V}$ intensity, 1-20 pulses at $20 \mathrm{~Hz}$ ) delivered by a pair of $\mathrm{Ag} / \mathrm{AgCl}$ wire electrodes, one placed in the intestinal wall, and the other in the organ bath. Membrane potential responses were amplified by a high-input impedance amplifier (MEZ8301, Nihon Kohden, Tokyo, Japan), displayed on an oscilloscope (CS 4025, Kenwood, Tokyo, Japan) and recorded on a thermal-array recorder (RTA-1100M, Nihon Kohden, Tokyo, Japan) for illustration and analysis.

Measurement of Substance $P(S P)$ release: Following a 60-min equilibration period, the perfusion of organ bath with PSS was stopped for $15 \mathrm{~min}$, and then the PSS in the organ bath $(4 \mathrm{ml})$ was removed. The collected PSS was immediately stored at $-80^{\circ} \mathrm{C}$ for subsequent measurement of SP levels. After the bath was refilled again with fresh PSS, an EFS $(0.5 \mathrm{msec}$ duration, $15 \mathrm{~V})$ with trains of 20 pulses at $20 \mathrm{~Hz}$ was applied five times at 3-min intervals over a 15min period. At the end of this period, the PSS was collected and stored at $-80^{\circ} \mathrm{C}$ for the subsequent measurement of SP levels. When effects of L-NAME $(200 \mu \mathrm{M})$, ODQ $(10 \mu \mathrm{M})$ and 8 -Br-cGMP $(3 \mathrm{mM})$ on the SP release were investigated, such experimental procedure was repeated $30 \mathrm{~min}$ after the treatment of these agents. If effect of NO $(10 \mu \mathrm{M})$ was tested, it was applied $10 \mathrm{sec}$ before EFS.

SP levels released from tachykininergic neurons were measured by a modified double-antibody solid-phase method by Porstmann and Kiessing [17] using an enzyme immunoassay kit (Peninsula Laboratories, Inc., Belmont, CA, U.S.A.), in accordance with the manufacture's instructions. Briefly, standard solution $(50 \mu l)$ in the SP enzyme immunoassay kit or sample solution $(50 \mu l)$ from the stored PSS were dispensed into 96-well protein A-corted immunoplate and the target peptides were determined using a streptavidin-conjugated horseradish peroxidase. The optical densities were read by a spectrophotometory at $450 \mathrm{~nm}$. The results were expressed in $\mathrm{fmol} / \mathrm{mg}$ wet wt.

Drugs: Apamin, atropine, $\mathrm{N}^{\mathrm{G}}$-nitro-L-arginine methyl ester (L-NAME), nifedipine, guanethidine, GR82334, 1H[1,2,4]oxadiazolo-[4,3-a]quinoxalin-1-one (ODQ) and 8bromoguanosine 3',5'-cyclic monophosphate (8-Br-cGMP) were obtained from Sigma Chemical Co. (St. Louis, MO, U.S.A.). Substance P (SP) and [D-Pro $\left.{ }^{4}, \mathrm{D}-\operatorname{Trp}^{7,9}\right]-\mathrm{SP}(4-11)$ were purchased from Peptide Institute, Inc. (Osaka, Japan). Nifedipine and ODQ were dissolved in ethanol and dimethyl sulfoxide (DMSO), respectively. Final concentrations of ethanol or DMSO in the bathing solution were less than $0.01 \%$ and had no effect on the membrane potential. All other drugs were dissolved in distilled water. The drug concentrations given in the text were final concentrations in the bathing solution.

A stock solution of $\mathrm{NO}$ was prepared by a modification of the method of Stark et al. [20]. Briefly, NO gas was injected into PSS which was previously deoxygenated by gassing with $\mathrm{He}$ for $2 \mathrm{hr}$, to give stock solutions of $\mathrm{NO}$ ranging from $0.01-1.0 \%(\mathrm{v} / \mathrm{v})$. A maximal possible concentration of $\mathrm{NO}$ in the $1.0 \%$ stock solution was calculated to be $420 \mu \mathrm{M}$ at room temperature [20]. The deoxygenated solution had no effect on membrane potential of the same cell. L-NAME, ODQ, [D-Pro ${ }^{4}$, D-Trp $\left.{ }^{7,9}\right]-S P(4-11)$ and GR82334 were applied by addition to the perfusing solution, while NO and 8-Br-cGMP were applied into the bath using syringe.

Statistical analysis: Data are expressed as mean \pm SEM, and $\mathrm{n}$ represents the number of experiments performed using different tissue preparations from different hamsters. The statistical difference between the mean values was analysed by unpaired Student's $t$-test for comparison of two groups, or one-way analysis of variance, followed by the Dunnett's test for multiple group comparisons. $P$ value of less than 0.05 was considered significant.

\section{RESULTS}

Membrane potential responses to electrical field stimulation: In the presence of atropine $(0.5 \mu \mathrm{M})$, guanethidine (1 $\mu \mathrm{M})$ and nifedipine $(0.1 \mu \mathrm{M})$, the circular smooth muscle cells of the hamster ileum displayed either electrically quiescence (in 131/235 cells) or spontaneous rhythmic potentials (in 104/235 cells), which represented slow wave activity with frequency of $8.9 \pm 0.2$ cycles $\mathrm{min}^{-1}$ and amplitude of $2.5 \pm 0.2 \mathrm{mV}$. The quiescent cells had an average resting membrane potential of $-45.5 \pm 0.4 \mathrm{mV}$, while the most negative potential between the slow waves in unquiescent cells was $-46.5 \pm 2.0 \mathrm{mV}$.

Electrical field stimulation of the intramural nerves (EFS; $0.5 \mathrm{msec}$ duration, $15 \mathrm{~V}$ intensity, single pulse) applied when cells were electrically quiescent, evoked inhibitory junction potentials (IJPs) in circular smooth muscle cells (Fig. 1A). The latency and time to peak of IJPs from the stimulus were $245 \pm 19 \mathrm{msec}(\mathrm{n}=27)$ and 2,045 $\pm 103 \mathrm{msec}$ $(n=27)$, respectively. If EFS with trains of 2 or more pulses was applied at $20 \mathrm{~Hz}$, amplitude of IJPs was increased with increasing number of pulses. However, EFS with trains of over 10 pulses rather decreased amplitude of IJPs, and EFS with trains of 20 pulses evoked excitatory junction potentials (EJPs) instead of IJPs (Fig. 1A).

Application of apamin $(100 \mathrm{nM})$, which is known to largely abolish the nitrergic IJPs [13], caused a significant depolarization of the membrane potential from $47.7 \pm 0.5$ to $43.3 \pm 0.8 \mathrm{mV}$ (paired $t$-test; $P<0.05 ; \mathrm{n}=8$ ), and abolished the NANC IJPs and unmasked EJPs, as shown in Fig. 1B. The EJPs evoked with single pulse stimulation had a amplitude of $1.0 \pm 0.7 \mathrm{mV}$, latency of $370 \pm 4.5 \mathrm{msec}$ and time to peak of $980 \pm 13 \mathrm{msec}(\mathrm{n}=7-12)$. Application of tetrodotoxin (TTX; $0.1 \mu \mathrm{M}$ ) abolished the EJP. 

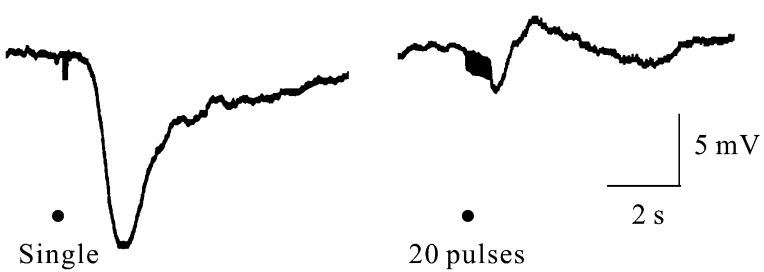

20 pulses

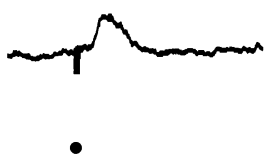

Single

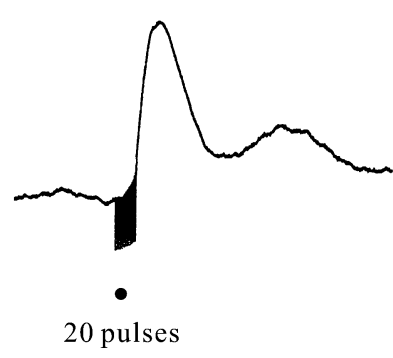

Fig. 1. Effect of apamin on the inhibitory junction potential (IJP) and excitatory junction potential (EJP) evoked by electrical field stimulation (EFS; $0.5 \mathrm{msec}$ duration, $15 \mathrm{~V}$ intensity). A: Representative IJP response evoked with single pulse (left panel) and EJP response evoked with trains of 20 pulses at 20 $\mathrm{Hz}$ (right panel). B: Representative EJP responses after the application of apamin $(100 \mathrm{nM})$. Note that treatment with apamin abolished the IJPs, and unmasked EJP. Traces of A and $\mathrm{B}$ were recorded from the same cell.

When the NK1 receptor antagonist $\left[\mathrm{D}-\mathrm{Pro}^{4}, \mathrm{D}-\mathrm{Trp}^{7,9}\right]-$ $\mathrm{SP}(4-11)(0.3-3 \mu \mathrm{M})$ was applied, they inhibited the EJP in a concentration dependent manner (Fig. 2), although these antagonists did not significantly alter the resting membrane potential, indicating that the EJPs arise from the activation of tachykininergic nerves.

Effects of L-NAME, ODQ, NO and 8-Br-cGMP on the tachykininergic EJP: To investigate if the tachykininergic excitatory transmissions from enteric motor neurons to smooth muscles were modulated by endogenous NO, effect of the NO synthase inhibitor L-NAME on the EJP were tested. In the presence of apamin $(100 \mathrm{nM})$, further treatment of L-NAME $(200 \mu \mathrm{M})$ had little or no effect on the resting membrane potential $(\mathrm{n}=7)$, but enhanced the tachykininergic EJPs (Fig. 3A and 3B). Mean amplitude of EJPs in the presence and absence of L-NAME $(200 \mu \mathrm{M})$ were 6.0 \pm 0.3 and $0.7 \pm 0.2 \mathrm{mV}(\mathrm{n}=6)$, respectively. The difference between the two values was statistically significant. To confirm that the increased amplitude of EJPs by L-NAME was due to the increase of tachykininergic response, effects of NK1 receptor antagonists on the increased EJPs were tested. Mean amplitudes of EJPs in the presence of L-NAME before and after the treatment of [D-Pro $\left.{ }^{4}, \mathrm{D}-\mathrm{Trp}^{7,9}\right]-\mathrm{SP}(4-$ 11) $(3 \mu \mathrm{M})$ or GR82334 $(3 \mu \mathrm{M})$ were $8.2 \pm 0.5$ and $0.6 \pm 0.3$
A

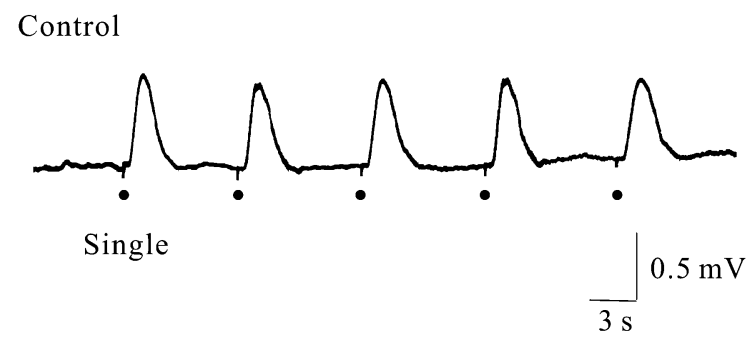

[D-Pro4,D-Trp7,9]-SP(4-11) $(3 \mu \mathrm{M})$

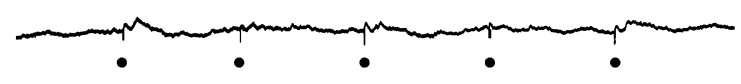

B

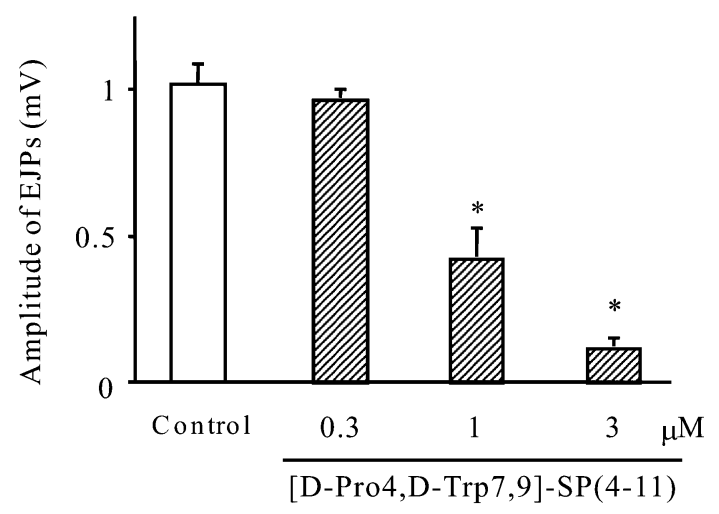

Fig. 2. Effect of $\left[\mathrm{D}-\mathrm{Pro}^{4}, \mathrm{D}-\mathrm{Trp}^{7,9}\right]-\mathrm{SP}(4-11)$ on the EJPs evoked by EFS with single pulse stimulation in the presence of apamin $(100 \mathrm{nM})$. A: Representative data before (Control) and after application of [D-Pro $\left.{ }^{4}, \mathrm{D}-\mathrm{Trp}^{7,9}\right]-\mathrm{SP}(4-11)(3 \mu \mathrm{M})$. B: Summary of the effects of $\left[\mathrm{D}-\mathrm{Pro}^{4}, \mathrm{D}-\mathrm{Trp}^{7,9}\right]-\mathrm{SP}(4-11)$. Each column and bar represents mean amplitude of EJPs and SEM of 7 observations, respectively. ${ }^{*} P<0.05, * * P<0.01$ compared to the control (Dunnett's test).

$\mathrm{mV}(\mathrm{n}=7)$ or $8.0 \pm 0.9 \mathrm{mV}$ and $1.6 \pm 0.9 \mathrm{mV}(\mathrm{n}=7)$, respectively. Thus, the pretreatment of NK1 receptor antagonists resulted in marked inhibition of EJP amplitude. These results suggested that endogenous NO may inhibit tachykininergic neuro-muscular transmission.

To explore if the nitrergic inhibition of the tachykininergic transmissions is mediated by a soluble guanylate cyclase, effect of its inihibitor, ODQ, on the EJP was tested. In the presence of apamin $(100 \mathrm{nM})$, treatment of ODQ (1$10 \mu \mathrm{M})$ had little or no effect on the resting membrane potential $(\mathrm{n}=12)$, but enhanced the tachykininergic EJPs. Mean amplitude of EJPs in the presence and the absence of ODQ $(10 \mu \mathrm{M})$ were $7.2 \pm 0.4$ and $2.1 \pm 0.3 \mathrm{mV}(\mathrm{n}=12)$, respectively (Fig. 3C); the difference between the two values was statistically significant, suggesting that soluble guanylate cyclase may mediate the nitrergic inhibition of the tachykininergic neuro-muscular transmission.

To confirm that NO and cGMP actually inhibit the 
A

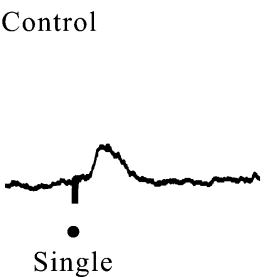

B

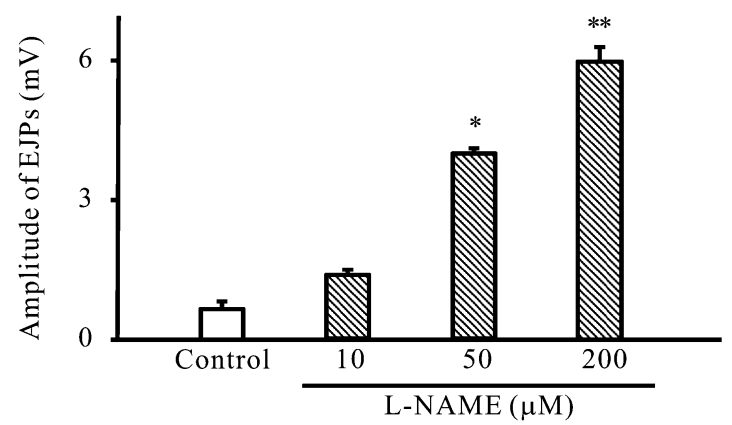

$\mathrm{C}$

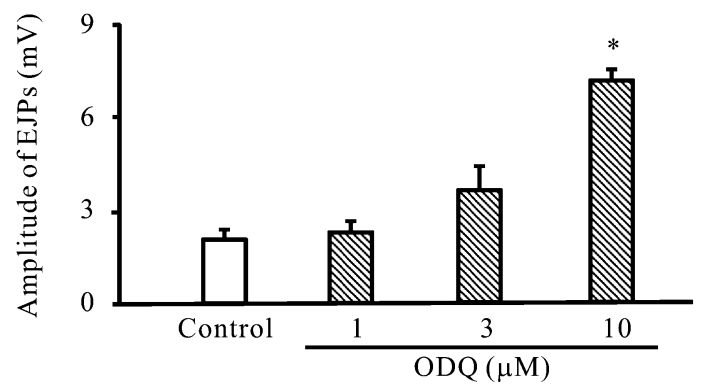

Fig. 3. Effects of L-NAME and ODQ on the EJPs evoked by EFS with single pulse stimulation. A: Representative data before (Control) and after application of L-NAME (L-NAME, 200 $\mu \mathrm{M})$ in the presence of apamin $(100 \mathrm{nM})$. B and C: Summary of the effects of L-NAME (10-200 $\mu \mathrm{M})$ and ODQ $(1-10 \mu \mathrm{M})$ on the EJP responses. Each column and bar represents mean amplitude of EJPs and SEM of 12 observations, respectively. $* P<0.05, * * P<0.01$ compared to the control (Dunnett's test).

NANC neuro-muscular transmission, effects of exogenously applied NO and the membrane permeable analog of cGMP, 8-Br-cGMP on the EJPs were investigated. In the presence of apamin $(100 \mathrm{nM})$ and L-NAME $(200 \mu \mathrm{M})$, NO $(1-10 \mu \mathrm{M})$ or 8 -Br-cGMP $(0.3-3 \mathrm{mM})$ did not significantly affect the resting membrane potentials, but concentrationdependently inhibited the NANC EJP (Fig. 4).

Effects of L-NAME, ODQ, NO and 8-Br-cGMP on the SP release: To test a possibility that NO regulates the tachykininergic neuro-muscular transmissions via pre-synaptic mechanisms, we investigated effects of L-NAME, ODQ, NO and 8-Br-cGMP on the release of SP induced by EFS. As shown in Table 1, basal amounts of SP release was significantly increased by EFS. Pretreatment of L-NAME (200 $\mu \mathrm{M})$ or ODQ $(10 \mu \mathrm{M})$ did not alter the basal amounts of SP release $[9.2 \pm 0.8$ and $8.8 \pm 0.9 \mathrm{fmol} / \mathrm{mg}$ wet wt $(\mathrm{n}=7$ each)
A

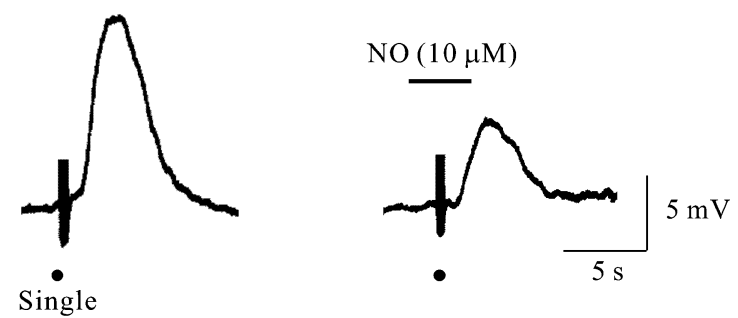

B

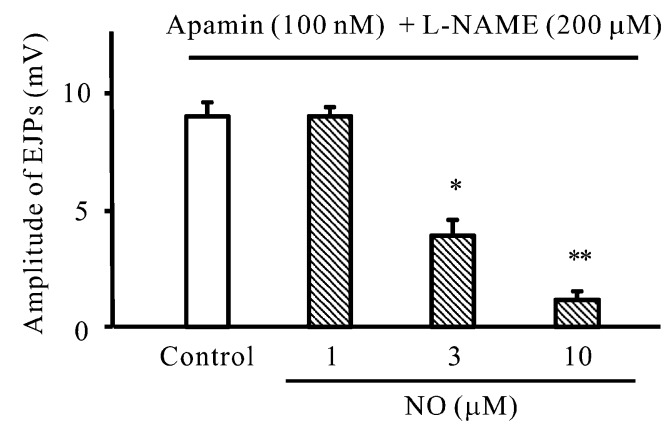

$\mathrm{C}$

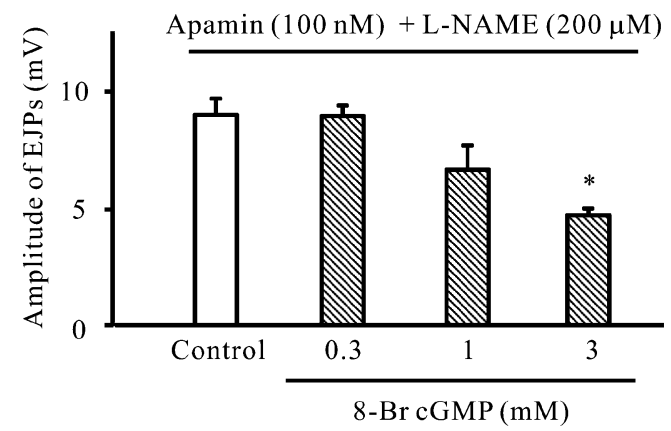

Fig. 4. Effects of exogenously applied NO and 8-Br-cGMP on EJPs. EJPs were evoked by EFS with single pulse stimulation in the presence of apamin $(100 \mathrm{nM})$ and L-NAME $(200 \mu \mathrm{M})$. A: Representative EJP responses before (left pannel) and after application of NO $(10 \mu \mathrm{M}$, right pannel). B and C: Summary of the effects of NO $(1-10 \mu \mathrm{M})$ and 8-Br-cGMP $(0.3-3 \mathrm{mM})$ on the EJP responses. Each column and bar represents mean amplitude of EJPs and SEM of 12 observations, respectively. $* P<0.05, * * P<0.01$ compared to the control (Dunnett's test).

in the presence of L-NAME and ODQ, respectively]. However, these agents significantly increased the amounts of EFS-induced SP release (Table 1). Exogenously applied NO $(10 \mu \mathrm{M})$ and 8-Br-cGMP (3 mM) did not significantly affect the basal amounts of SP, but significantly inhibited the EFS-induced release of SP (Table 1). These results suggest that endogenous NO may regulate SP release from enteric neurons via a guanylate cyclase-cGMP-dependent mechanism.

\section{DISCUSSION}

Enteric neurons release a number of excitatory and inhibitory neurotransmitters to regulate intestinal motility. NO has been well documentated as an inhibitory neurotransmit- 
Table 1. Effects of L-NAME, ODQ, NO and 8-Br cGMP on SP release

\begin{tabular}{lcc}
\hline & $\mathrm{n}$ & $\begin{array}{c}\text { SP release } \\
\text { (fmol/mg wet wt) }\end{array}$ \\
\hline Basal & 7 & $9.0 \pm 0.8$ \\
EFS & 7 & $17.2 \pm 0.8^{*}$ \\
EFS + L-NAME $(200 \mu \mathrm{M})$ & 7 & $25.6 \pm 1.0^{* *}$ \\
EFS + ODQ $(10 \mu \mathrm{M})$ & 7 & $24.1 \pm 1.1^{* *}$ \\
EFS + NO $(10 \mu \mathrm{M})$ & 7 & $9.6 \pm 0.7$ \\
EFS + 8-Br cGMP $(3 \mu \mathrm{M})$ & 7 & $9.8 \pm 0.8$ \\
\hline
\end{tabular}

Values are means \pm SEM. n, no. of preparations. ${ }^{*} P<0.05$, ** $P<0.01$ compared with control.

ter in all gastrointestinal regions including small intestine $[6,16]$. It is well known that released NO from enteric neurons directly act on smooth muscles to produce membrane hyperpolarization in various intestinal regions of various species [7, 13, 14, 19, 24, 26]. The findings of the present study extend the inhibitory mechanism of the nitrergic neurons and suggest that endogenous NO act on the tachykininergic neurons to reduce the release of SP through guanylate cyclase-cGMP-dependent pathway in the hamster ileum. These conclusions are supported by the following observations. Both NOS and soluble guanylate cyclase inhibitors (L-NAME and ODQ, respectively) significantly enhanced the tachykininergic EJP and release of SP, but exogenously applied NO and 8-Br-cGMP inhibited the EJP and the release of SP.

In the present study, tachykininergic EJPs were recorded in the presence of apamin, which largely abolish IJPs mediated by nitrergic neurons [13]. The results that exogenously applied NO or 8-Br-cGMP did not induce any membrane hyperpolarization, indicated that direct action of $\mathrm{NO}$ on the smooth muscle cells was effectively suppressed by the treatment of apamin. Therefore, under these conditions, enhancement of EJPs by L-NAME and ODQ is thought to be due to action of these agents on the tachykininergic neurons, but not on the smooth muscle cells. Actually, these agents significantly increase the amount of released SP. On the other hand, exogenously applied NO and 8-Br-cGMP significantly inhibited the tachykininergic EJPs and the release of SP. Thus, endogenous NO released from nitrergic neurons act on not only smooth muscles but also the tachykininergic neurons to inhibit SP release through guanylatecyclase-cGMP pathway.

In general, cGMP activates protein kinase $\mathrm{G}$ (PKG), which is known to phosphorylate various proteins including ion channels to modulate cellular functions. In rat cortical neurons, NO is suggested to inhibit GABA release by cGMP-dependent signaling and inhibition of neuronal $\mathrm{Ca}^{2+}$ channels [8]. In human neuroblastome cells, NO is reported to inhibit N-type voltage-gated $\mathrm{Ca}^{2+}$ channels (VGCC) through cGMP/PKG pathway [1]. Since N-type $\mathrm{Ca}^{2+}$ channels have a primary role for $\mathrm{Ca}^{2+}$ influx leading to release of neurotransmitters [18], this type of $\mathrm{Ca}^{2+}$ channels in the tachykininergic neurve terminals of hamster ileum may be target for the NO. Consistent with this idea, there is an evidence that the release of SP from enteric neurons in the guinea-pig proximal colon is inhibited by $\omega$-conotoxin GVIA, a N-type VGCC blocker [9].

It has been reported that ascending interneurons being immunoreactive for NO synthase were identified together with excitatory motor neurons, which were immunoreactive for SP, in circular muscle layers of the guinea-pig colon [11]. In the hamster ileum, immunoreactive cell body and nerve fibers for NO synthase and SP in the myenteric plexus have been also identified, and these immunoreactive neurons densely distributed throughout the ileum [21]. These observations support a possibility that nitrergic neurons interact with tachykininergic neurons. However, direct evidence for the close association of the both neurons has not yet been reported, and further experiments such as double immuno-histchemical staining for NO synthase and SP is needed to identify the precise alignment of and distance between nitrergic and tachykininergic neurons. It is also interesting to explore that inhibitory regulation of transmitter release by NO is specific for tachykininergic neuron in the hamster ileum.

In the hamster ileum, SP mediates NANC transmissions from enteric motor neurons to smooth muscles, since NANC EJP was markedly inhibited by SP receptor antagonists [2, present study]. Recent evidence suggests that interstitial cells of Cajal (ICC) are involved in the neuromuscular transmission [23]. Wang et al. [22] have indicated that there is a physical, close association between varicose nerve terminals and ICC and gap junctions between ICC and smooth muscle cells, suggesting that neurotransmitters from enteric motor neurons act primarily on ICC, and then excitatory signals generated in ICC are conducted to the smooth muscle cells via gap junctions. Actually, cholinergic and nitrergic neuro-muscular transmissions in guinea pig stomach have been suggested to involve ICC (for review, see [25]). Since ICC express NK1 receptors [4], it is not excluded the possibility that ICC is involved in the tachykininergic neuro-muscular transmissions as an intermediate in the hamster ileum. If so, NO released from enteric neurons might act on ICC and then inhibit excitatory signals produced by SP in ICC.

In conclusion, the present study suggests that endogenous NO inhibits tachykininergic transmissions from enteric motor neurons to smooth muscle cells in the hamster ileum. NO may exert its effects prejunctionally by inhibiting the release of SP via a guanylate cyclase-cGMP-dependent pathway. Such inhibitory regulation of transmitter release may be important to decrease spontaneous activity of small intestinal smooth muscles brought about by tachykininergic neurons $[12,15]$.

ACKNOWLEDGMENTS. This work was partly supported by a Grant-in-Aid Scientific Research from the Ministry Education, Culture, Sports, Science and Technology, Japan (No. 20580322 and 22380159). 


\section{REFERENCES}

1. D’Ascenzo, M., Martinotti, G., Azzena, G. B. and Grassi, C. 2002. cGMP/protein kinase G-dependent inhibition of N-type $\mathrm{Ca}^{2+}$ channels induced by nitric oxide in human neuroblastoma IMR32 cells. J. Neurosci. 22: 7485-7492.

2. El-Mahmoudy, A., Matsuyama, H., Khalifa, M., Shimizu, Y. and Takewaki, T. 2003. Tachykinins mediate non-adrenergic, non-cholinergic excitatory neurotransmission to the hamster ileum via NK1 and NK2 receptors. Life Sci. 73: 1939-1951.

3. Hebeiss, K. and Kilbinger, H. 1998. Nitric oxide-sensitive soluble guanylate cyclase inhibits acetylcholine release and excitatory motor transmission in the guinea-pig ileum. Neuroscience 82: 623-629.

4. Iino, S., Ward S. M. and Sanders, K. M. 2004. Interstitial cells of Cajal are functionally innervated by excitatory motor neurones in the murine intestine. J. Physiol. 556: 521-530.

5. Ivancheva, H., Itzev, D., Lolova, I. and Radomirov, R. 1998. Contribution of nitric oxide and substance $\mathrm{P}$ to nonadrenergic, noncholinergic transmission in the guinea pig ileum. Gen. Pharmacol. 31: 101-105.

6. Kanada, A., Hata, F., Suthamnatpong, N., Maehara, T., Ishii, T., Takeuchi, T. and Yagasaki, O. 1992. Key roles of nitric oxide and cyclic GMP in nonadrenergic and noncholinergic inhibition in rat ileum. Eur. J. Pharmacol. 216: 287-292.

7. Koh, S. D., Campbell, J. D., Carl, A. and Sanders, K. M. 1995. Nitric oxide activates multiple potassium channels in canine colonic smooth muscle. J. Physiol. 489: 735-743.

8. Lee, J.-J. 2009. Nitric oxide modulation of GABAergic synaptic transmission in mechanically isolated rat auditory cortical neurons. Korean J. Physiol. Pharmacol. 13: 461-467.

9. Lippi, A., Santicioli, P., Criscuoli, M. and Maggi, C. A. 1998. Depolarization evoked co-release of tachykinins from enteric nerves in the guinea-pig proximal colon. Naunyn Schmiedeberg's Arch. Pharmacol. 357: 245-251.

10. Liu, L. W. C. and Huizinga, J. D. 1993. Electrical coupling of circular muscle to longitudinal muscle and interstitial cells of Cajal in canine colon. J. Physiol. 470: 445-461.

11. Lomax, A. E. and Furness, J. B. 2000. Neurochemical classification of enteric neurons in the guinea-pig distal colon. Cell Tissue Res. 302: 59-72.

12. Martinez-Cuesta, M. A., Esplugues, J. V. and Whittle, B. J. 1996. Modulation by nitric oxide of spontaneous motility of the rat isolated duodenum: role of tachykinins. Br. J. Pharmacol. 118: 1335-1340.

13. Matsuyama, H., Thapaliya, S. and Takewaki, T. 1999. Cyclic GMP-associated apamin-sensitive nitrergic slow inhibitory junction potential in the hamster ileum. Br. J. Pharmacol. 128: 830-836.

14. Matsuyama, H., Unno, T., El-Mahmoudy, A. M., Komori, S., Kobayashi, H., Thapaliya, S. and Takewaki, T. 2002. Peptidergic and nitrergic inhibitory neurotransmissions in the hamster jejunum: regulation of vasoactive intestinal peptide release by nitric oxide. Neuroscience 110: 779-788.

15. Mulè, F., D’Angelo, S., Tabacchi, G. and Serio, R. 2000. Involvement of tachykinin NK2 receptors in the modulation of spontaneous motility in rat proximal colon. Neurogastroenterol. Motil. 12: 459-466.

16. Osthaus, L. E. and Galligan, J. J. 1992. Antagonists of nitric oxide synthesis inhibit nerve-mediated relaxations of longitudinal muscle in guinea pig ileum. J. Pharmacol. Exp. Ther. 260: 140-145.

17. Porstmann, T. and Kiessig, S. T. 1992. Enzyme immunoassay techniques an overview. J. Immunol. Methods 150: 5-21.

18. Reid, C. A., Bekkers, J. M. and Clements, J. D. 2003. Presynaptic $\mathrm{Ca}^{2+}$ channels: a functional patchwork. Trends Neurosci. 26: $683-687$.

19. Serio, R., Mulè, F., Postorino, A., Vetri, T. and Bonvissuto, F. 1996. Apamin-sensitive and -insensitive components of inhibitory junction potentials in rat caecum: role of nitric oxide. $J$. Auton. Pharmacol. 16: 183-189.

20. Stark, M. E., Bauer, A. J. and Szurszewski, J. H. 1991. Effect of nitric oxide on circular muscle of the canine small intestine. J. Physiol. 444: 743-761.

21. Toole, L., Belai, A. and Burnstock, G. 1998. A neurochemical characterisation of the golden hamster myenteric plexus. Cell Tissue Res. 291: 385-394.

22. Wang, X. Y., Sanders, K. M. and Ward, S. M. 1999. Intimate relationship between interstitial cells of Cajal and enteric nerves in the guinea-pig small intestine. Cell Tissue Res. 295: 247-256.

23. Ward, S. M., Beckett, E. A. H., Wang, X., Baker, F., Khoyi, M. and Sanders, K. M. 2000. Interstitial cells of Cajal mediate cholinergic neurotransmission from enteric motor neurons. $J$. Neurosci. 20: 1393-1403.

24. Ward, S. M., Dalziel, H. H., Khoyi, M. A., Westfall, A. S., Sanders, K. M. and Westfall, D. P. 1996. Hyperpolarization and inhibition of contraction mediated by nitric oxide released from enteric inhibitory neurones in guinea-pig taenia coli. $\mathrm{Br}$. J. Pharmacol. 118: 49-56.

25. Ward, S. M. and Sanders, K. M. 2006. Involvement of intramuscular interstitial cells of Cajal in neuroeffector transmission in the gastrointestinal tract. J. Physiol. 576: 675-682.

26. Watson, M. J., Lang, R. J., Bywater, R. A. and Taylor, G. S. 1996. Characterization of the membrane conductance changes underlying the apamin-resistant NANC inhibitory junction potential in the guinea-pig proximal and distal colon. J. Auton. Nerv. Syst. 60: 31-42.

27. Wiklund, C. U., Olgart, C., Wiklund, N. P. and Gustafsson, L. E. 1993. Modulation of cholinergic and substance P-like neurotransmission by nitric oxide in the guinea-pig ileum. $\mathrm{Br} . J$. Pharmacol. 110: 833-839.

28. Yunker, A. M. and Galligan, J. J. 1996. Endogenous NO inhibits NANC but not cholinergic neurotransmission to circular muscle of guinea-pig ileum. Am. J. Physiol. 271: G904-G912. 